\title{
Determination of Planeness and Bending of Optical Flats
}

\section{Walter B. Emerson}

\begin{abstract}
The true contours, undistorted by gravitational bending, were determined for four $10^{5 / 8}$-inch-diameter standard optical flats of fused quartz. The bending deflections of these flats were determined by a method based upon the differential bending with thickness of the flats. Bending deflection curves of a flat supported ac three points equidistant from the center of the flat and equidistant from each other were obtained. The locus of the bending deflections at the center of a flat, similar]y supported but with supports at different distances from the center, approximates a straight line. This paper describes the method used to obtain the true contours and the bending deflection curves of the flats, and compares the bending values so determined with theoretically derived values.
\end{abstract}

\section{Introduction}

One activity of the National Bureau of Standards is to determine the deviation from a plane of surfaces of optical flats submitted for calibration. Usually these are disks of fused quartz used as working standards by makers of optical elements. Disks 10 in. in diameter, with specified maximum deviation from a plane of 0.1 fringe (approximately 0.000,001 in.) are frequently submitted. These are tested by interferometric comparison with the Bureau's 10 5/ in-diameter fused quartz standard planes, the contour of which should be known to a few hundred ths of a fringe to make the tests valid to the required tolerance.

It is commonly assumed that by intercomparison of three surfaces, the deviation of each surface from a plane may be determined. This is true if the flats are similarly supported and are identical except for differences in surface contour. Otherwise, consideration must be given to the deflection of each flat when supported in its position of test. Even in the case of support of the lower flat in mercury, some bending attributable to nonuniform distribution of forces by the weight of the upper flat and by surface-tension effects at the edge of the lower flat is to be expected. The theory of the bending of circular plates has been developed by Nádai [1, 2, $3]^{1}$ and Timoshenko [4], and from these theoretical considerations an equation was formulated for circular plates supported at the vertices of an inscribed equilateral triangle whereby the gravitational bending deflection along a diametric line parallel to two of the supports may be determined with respect to a plane passing through the points of support. The results, based on a value $\nu=0.14$ for Poisson's ratio, are plotted as a dimensionless function from which the bending along a given diameter of a quartz plate may be readily determined.

In addition to deflections caused by bending, deflections are present because of shearing stresses and stress normal to the face of the plate. When these stresses are all taken into account for the case of a plate simply supported at the edges, Timoshenko [4] gives the following equation for the lateral deflection:

$w=\frac{q}{64 D}\left(a^{2}-r^{2}\right)\left(\frac{5+\nu}{1+\nu} a^{2}-r^{2}\right)+\frac{q h^{2}}{8 D} \frac{3+\nu}{6\left(1-\nu^{2}\right)}\left(a^{2}-r^{2}\right)$,

\footnotetext{
Figures in brackets indicate the literature references at the end of this paper.
}

where

$w=$ lateral deflection,

$q=$ lateral pressure,

$D=$ flexural rigidity $=E h^{3} / 12\left(1-\nu^{2}\right)$,

$E=$ Young's modulus,

$a=$ plate radius,

$r=$ distance from center,

$h=$ plate thickness,

$\nu=$ Poisson's ration.

For plates acted on by gravitational forces, the lateral pressure is given by

$$
q=\rho g h,
$$

where $\rho$ is the density and $g$ the acceleration of gravity. Substituting (2) into (1) and replacing $D$ by $E h^{3} / 12\left(1-\nu^{2}\right)$ gives

$$
\begin{aligned}
w= & \left(\frac{1}{h^{2}}\right) \frac{\rho g}{16 E} 3\left(1-\nu^{2}\right)\left(a^{2}-r^{2}\right)\left(\frac{5+\nu}{1+\nu} a^{2}-r^{2}\right)+ \\
& \frac{\rho g}{4 E}(3+\nu)\left(a^{2}-r^{2}\right) .
\end{aligned}
$$

It is seen that the first term in this equation varies inversely as the thickness squared and the second term is independent of thickness. Relations similar to (3), but depending differently on $r$, apply when the plate is supported by other means than simple support. One can express the deflection of the plate as

$$
w=\frac{1}{h^{2}} f_{b}(r)+f_{s}(r),
$$

where the functions $f_{b}$, for bending, and $f_{s}$, for shear and lateral pressure depend only on the means of support

It should be pointed out that eq (3) does not include the effect of local deformation near points of concentrated load. These will be shown to be small, by measurement, for the plates tested.

Relationship (4) furnishes a basis for determining the true contour, undistorted by bending, shear, and lateral pressure effects, of the surfaces of optical flats.

A method for determining the true contour and the bending (the first term in relation (4)) of optical flats is presented and this method is applied to determinations of contour and to evaluation of the bending of four optical flats, and compares the bending values so determined with the values obtained according to theory. 


\section{Methods}

\subsection{Determination of True Contours}

If a circular plate, resting on supports at the vertices of an inscribed equilateral triangle, supports a similar plate on supports directly above those for the lower plate, the surfaces of the plates tend to sag. If the surfaces were originally plane, the upper surface of the lower plate will now be concave, and the adjacent surface of the upper plate will be convex by an equal amount if the plates are of equal thickness, and by a greater amount if the upper plate is thinner. With three transparent plates of like material, properties, and diameter the true contour of their surfaces (that is, if the plates were supported uniformly and did not bend) may be determined by intercomparison of the plates, but no knowledge of the amount the plates bend will be obtainable. However, intercomparison of a series of plates that differ only in thickness will yield not only the true contour of the surfaces but also an evaluation of the change in contour (bending deflection) of the surfaces caused by the weight of the plates.

The following fused-quartz optical flats having a nominal diameter of $105 / 8$ in. were available for inter comparison in this investigation:

\begin{tabular}{|c|c|c|c|}
\hline Flat number & Diameter & $\begin{array}{c}\text { Thickness } \\
(t)\end{array}$ & $t^{2}$ \\
\hline & Inches & Inches & \\
& 10.66 & 1.428 & 2.039 \\
1 & 10.61 & 1.626 & 2.644 \\
2 & 10.59 & 2.50 & 6.250 \\
4 & 10.58 & 2.50 & 6.250 \\
\hline
\end{tabular}

Flats 1 and 2, which have served as standard planes at the Bureau for the past 30 years, contain numerous strias and inclusions, and the quality of their materials is inferior to that of flat 3 , which was recently purchased, and also of flat 4, which was loaned for this investigation by the maker of flat 3 . Flats 3 and 4 are slightly wedge-shaped, and the listed thickness is the average of measurements at several places around the circumference. For the purpose of this investigation, flats 3 and 4 are considered identical, except for difference in contour.

Based on the relationship that the bending deflection varies inversely as the square of the thickness, the deflection of flat 1 will be 1.30 times that of flat 2 and 3.07 times that of 3 or 4 ; the deflection of flat 2 will be 2.36 times that of 3 or 4 .

By intercomparing flats 1,2 , and 3 in the relative positions shown in figure 1 (series 1 ) the true contour of flat 1 may be obtained directly from interferometric measurements of the sum of the contours of adjacent surfaces of the supported flats.

Let:

Each flat be supported at three points equidistant from the center and equidistant from each other; the supports for the upper flat be directly above those
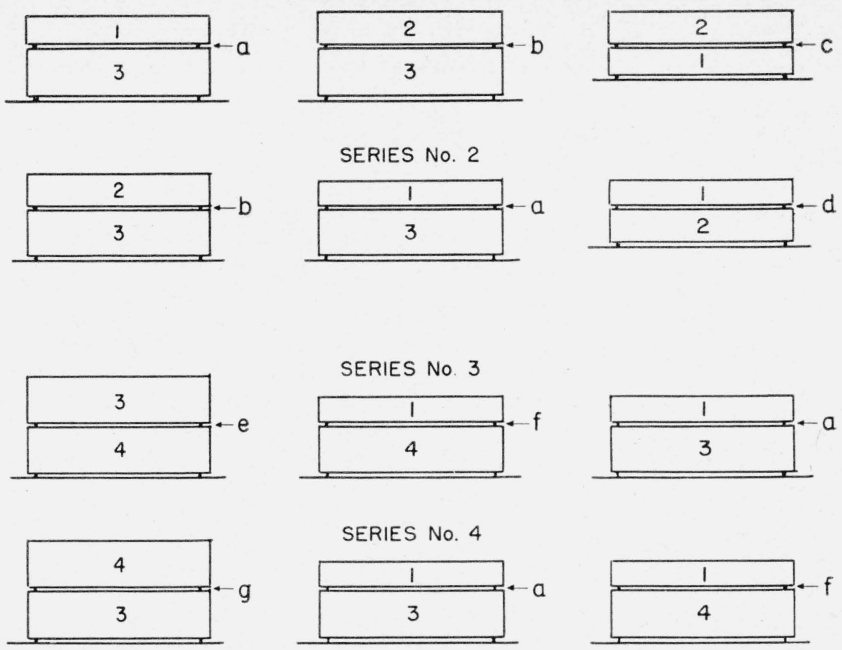

SERIES No. 4
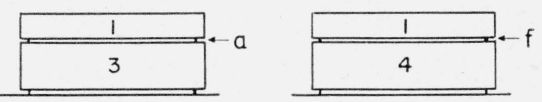

Figure 1. Series 1-Combinations of flats to determine the true contour of Numbers $1,2,3$, and 4.

for the lower flat; the algebraic sum of the contours of adjacent surfaces be measured along a diametric line parallel to two of the supports of each flat;

$C_{1} ; C_{2} ; C_{3}=$ true contours, undistorted by bending, of flats 1,2 , and 3 ;

$a ; b ; c=$ measured sum of the contours of 1 on $3 ; 2$ on 3 ; and 2 on 1 , respectively; $\pm D=$ bending deflection of flat 3 (also of 4 );

$\pm D_{1}=$ bending deflection of flat $1= \pm 3.07 \mathrm{D}$;

$\pm D_{2}$ =bending deflection of flat $2= \pm 2.36 \mathrm{D}$;

$S=$ shearing deflection of each plate;

+ value $=$ downward deflection;

Then :

- value $=$ upward deflection.

$$
\begin{aligned}
& C_{1}+D_{1}+S+C_{3}-D-S=a \\
& C_{2}+D_{2}+S+C_{3}-D-S=b \\
& C_{2}+D_{2}+S+C_{1}-D_{1}-S=c
\end{aligned}
$$

and:

$$
\begin{aligned}
& C_{1}=\frac{a-b+c}{2} \\
& C_{2}-0.71 D=\frac{-a+b+c}{2} \\
& C_{3}+2.07 D=\frac{a+b-c}{2}
\end{aligned}
$$

Whereas $C_{1}$ is obtained directly in terms of measurable quantities $a, b, c$, values for $C_{2}$ and $C_{3}$ cannot be determined from these measurements unless the bending deflection $D$ is known. Determinations that require correction for $D$ will be referred to as indirect determinations.

Similarly, series 2, 3, and 4, figure 1, yield direct values of $C_{2}, C_{3}$, and $C_{4}$, respectively, and yield also indirect values of $C_{1}, C_{3}$, and $C_{4}$. 


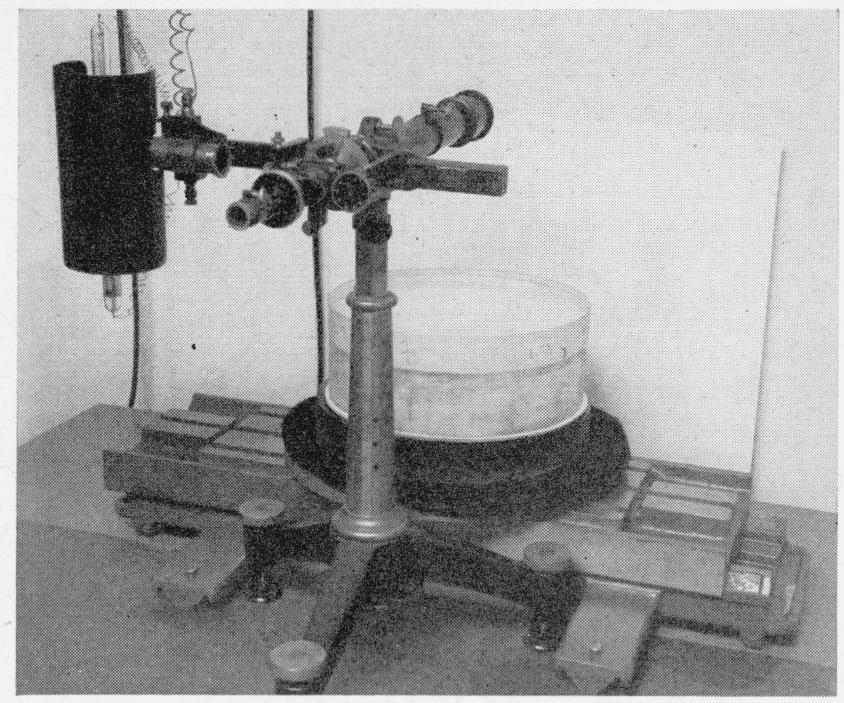

FIGURE 2. Setup for the determinations of contour and bending.

\subsection{Determination of Bending Deflection}

Since the bending deflection (given by the first term of eq (4) varies inversely as the thickness squared the bending deflections $D_{1}$ and $D$ of flats 1 and 3 , respectively, may be determined from measurements of the sum of the contours with flat 1 above and beneath flat 3 . If the measured values are $a$ with flat 1 above and $a^{\prime}$ with flat 3 above:

$C_{1}+3.07 D+S+C_{3}-D-S=a ; \quad C_{1}+C_{3}+2.07 D=a ;$

and

$C_{3}+D+S+C_{1}-3.07 D-S=a^{\prime} ; \quad C_{1}+C_{3}-2.07 D=a^{\prime}$.

From eq (5) and (6),

$4.14 D=a-a^{\prime} ; D=0.242\left(a-a^{\prime}\right) ; D_{1}=0.743\left(a-a^{\prime}\right)$.

Had a thinner flat, 0.75 in. thick, been available for comparison with flat 3 , the value $\left(\alpha-a^{\prime}\right)$, from the measurements would equal 20.2 times the deflection of flat 3 , thus increasing appreciably the accuracy of the determinations of bending.

\section{Procedure for Comparing the Flats}

One flat was supported, with its optical surface up, by three $1 / 8$-in.-diameter paper disks spaced equidistant from the center of the flat and equidistant from each other on the glass plate shown in figure 2. A second flat, with its optical surface down, was supported on the first flat by three similar disks directly above the supports of the lower flat. The combination was placed on a movable carriage beneath a Pulfrich viewing instrument [5]. By means of a hand crank operating through reduction gears, the combination could be moved slowly and smoothly across the field of the viewing instrument, which

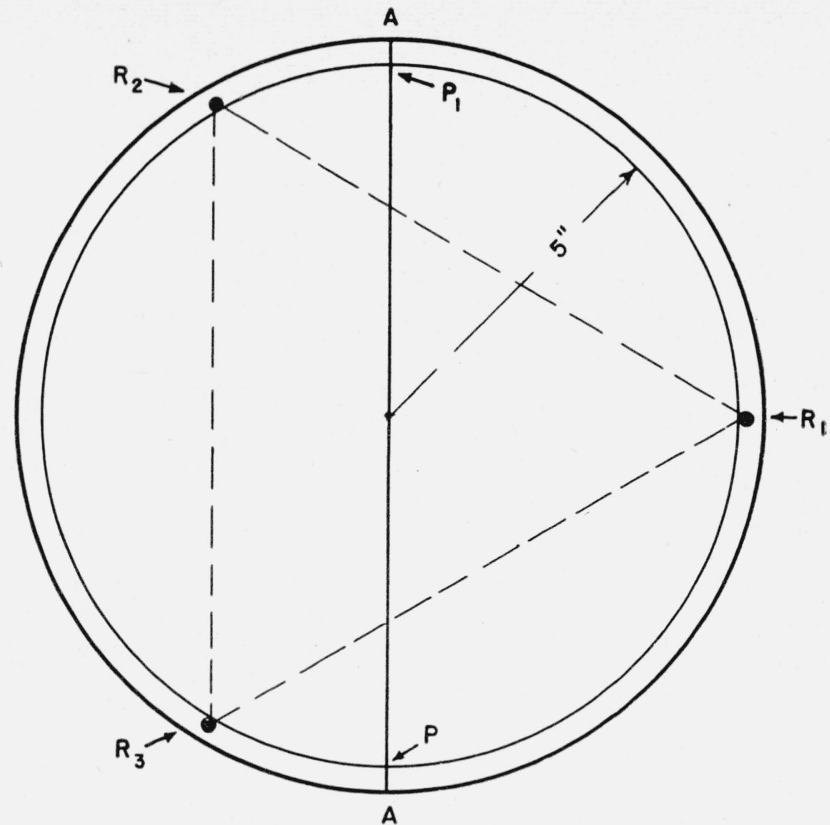

Figure 3. Position of diametric line $\mathrm{A}-\mathrm{A}$ relative to the points of support, and of points $\mathrm{P}$ and $\mathrm{P}_{1}$ between which the measurements were made.

served both as a source of monochromatic light and as a means for measuring deviations of the resulting fringes from a straight line, that is, the algebraic sum of the contours of adjacent surfaces. Desired fringe widths were obtained by selecting paper disks of proper relative thickness. Widths corresponding to 300 divisions of the micrometer head of the viewing instrument proved satisfactory in this work.

Measurements for each combination of flats were made between points $\mathrm{P}$ and $\mathrm{P}_{1}$, figure 3 , which are 5 in. from the center and lie on a definite diametric line AA that is parallel to supports $R_{2}$ and $R_{3}$. The sum of the contours was determined for the inner 10-in. diameter surface of the flats rather than for the entire surface because of irregularities in the outlying area that might affect the accuracy of measurements.

The deviation of a fringe from a straight line passing through the intersections of that fringe with the circumference of the 10-in. surface was measured in terms of divisions of the micrometer head of the viewing instrument. The number of divisions thus measured (given the proper sign to indicate the direction of curvature) divided by the divisions between successive fringes is the algebraic sum of the contours in terms of fringes. Determinations were made at eleven points along the diameter.

Comparisons were made in a temperature-controlled room with the flats enclosed in an insulated container (not shown in fig. 2) covered inside and outside with aluminum-coated paper. By uncovering a small opening in the top of the container, fringes were observed and measured. The usual procedure was to set up the flats during the forenoon, measure the combination several times in the afternoon when thermal conditions were stabilized, and 
repeat the observations the following morning, thus completing one set of observations. The flats were then reset and the procedure repeated. The final values for the contours are based on an average of five sets of observations for each combination of flats. The maximum deviation of the individual sets from the mean for a given combination in no case exceeded 0.017 fringe for measurements at the center; and the average deviation from the mean was 0.005 fringe.

\section{Measurements and Results}

\subsection{True Contours}

\section{a. Direct Determinations}

To test the validity of the methods described in section 2.1 for determining the true contours of the four standard flats, the differences $a, b, c, d, e, f, g$ (fig. 1, series 1, 2, 3, and 4) were determined by interferometric comparison when the flats were supported at three points located as follows:

5.06 in. $(0.95 \times$ radius $r)$ from the center

3.5 in. $(0.66 \times$ radius $r)$ from the center.

From these measurements the true contours of the flats were obtained from equations

$$
\begin{aligned}
C_{1}=\frac{a-b+c}{2}, \quad C_{2}= & \frac{b-a+d}{2}, \\
& C_{3}=\frac{e-f+a}{2}, \quad C_{4}=\frac{-a+f+g}{2} .
\end{aligned}
$$

Additional values were obtained with the flats supported at $0.95 r$ by substituting flat 2 for flat 1 in series 3 and 4 , and flat 4 for flat 3 in series 1 and 2 .

The resulting determinations of the true contour of flat 1 are given in table 1 . The two determinations at $0.95 r$, columns 2 and 3 , differ by only a few units in the third decimal place. Column 4 gives the mean of the determinations at $0.95 r$. The contours determined with supports at $0.66 r$ are given in column 5. Column 6 gives the difference between the contours determined for the two conditions of support, and indicates that true contours obtained by this method are nearly the same whether determined with supports at $0.95 r$ or at $0.66 r$. Column 7 gives the mean of the direct determinations of true contour for these two supports.

The magnitude of the differences given in columns 4 and 6 for this flat are representative of those similarly obtained for flats 2,3 , and 4 .

\section{b. Indirect determinations}

Intercomparison of the various combinations in section 2.1 for different positions of the supports yields some equations that include terms $0.71 D$, $1.36 D$, or $2.07 D$, where $D$ is the bending deflection of 2.5-in.-thick flats 3 or 4 at points between $P$ and $\mathrm{P}_{1}$, figure 3 , relative to the bending deflection at points $\mathrm{P}, \mathrm{P}_{1}$. Values for $D$ were obtained from determinations described in section 4.2. The magnitude of $D$ will depend upon the position of the supports and the place of measurement. By substituting the values thus determined for $D$ in the equations that include a term for the bending deflection, additional values of the true contours of the four flats were obtained.

TABLE 1. True contour (in fringes) of the central 10-in.-diameter surface of optical flat 1 by direct and indirect methods

\begin{tabular}{|c|c|c|c|c|c|c|c|c|c|c|c|c|c|c|c|c|c|}
\hline \multirow{5}{*}{$\begin{array}{l}\text { Distance } \\
\text { from } P\end{array}$} & \multicolumn{6}{|c|}{ Direct determinations } & \multicolumn{9}{|c|}{ Indirect determinations (corrected for bending term) } & \multirow{5}{*}{$\begin{array}{l}\text { Differ- } \\
\text { ence } \\
7-16\end{array}$} & \multirow{5}{*}{$\begin{array}{l}\text { Con- } \\
\text { tour } \\
\text { (mean } \\
7 \text { and } \\
16)\end{array}$} \\
\hline & \multicolumn{4}{|c|}{ Position of supports } & \multirow{4}{*}{$\begin{array}{c}\text { Differ- } \\
\text { ence } \\
4-5\end{array}$} & \multirow{4}{*}{$\begin{array}{l}\text { Mean } \\
4 \text { and } 5\end{array}$} & \multicolumn{7}{|c|}{ Position of supports } & \multirow{4}{*}{$\begin{array}{l}\text { Differ- } \\
\text { ence } \\
11-14\end{array}$} & \multirow{4}{*}{$\begin{array}{l}\text { Mean } \\
11 \text { and } \\
14\end{array}$} & & \\
\hline & \multirow{3}{*}{\multicolumn{2}{|c|}{$0.95 r$}} & \multirow{3}{*}{$\begin{array}{c}\text { Mean } \\
2 \text { and } 3\end{array}$} & \multirow{3}{*}{$0.66 r$} & & & \multicolumn{4}{|c|}{$0.95 r$} & \multicolumn{3}{|c|}{$0.66 r$} & & & & \\
\hline & & & & & & & \multicolumn{3}{|c|}{$\begin{array}{l}\text { For corresponding } \\
\text { bending terms- }\end{array}$} & \multirow{2}{*}{$\begin{array}{c}\text { Mean } \\
8,9 \text { and } \\
10\end{array}$} & \multicolumn{2}{|c|}{$\begin{array}{l}\text { For correspond- } \\
\text { ing bending } \\
\text { terms- }\end{array}$} & \multirow{2}{*}{$\begin{array}{c}\text { Mean } \\
12 \text { and } \\
13\end{array}$} & & & & \\
\hline & & & & & & & $(2.07 \mathrm{D})$ & $(0.71 \mathrm{D})$ & $(0.71 \mathrm{D})$ & & $(2.07 \mathrm{D})$ & $(0.71 \mathrm{D})$ & & & & & \\
\hline 1 & 2 & 3 & 4 & 5 & 6 & 7 & 8 & 9 & 10 & 11 & 12 & 13 & 14 & 15 & 16 & 17 & 18 \\
\hline $\begin{array}{c}\text { Inches } \\
0.0 \\
.5 \\
1.5 \\
2.5 \\
3.5\end{array}$ & $\begin{array}{l}0.000 \\
-.021 \\
-.069 \\
-.084 \\
-.111\end{array}$ & $\begin{array}{r}0.000 \\
-.019 \\
-.065 \\
-.081 \\
-.112\end{array}$ & $\begin{array}{l}0.000 \\
-.020 \\
-.067 \\
-.083 \\
-.112\end{array}$ & $\begin{array}{l}0.000 \\
-.021 \\
-.061 \\
-.079 \\
-.104\end{array}$ & $\begin{array}{r}0.000 \\
+.001 \\
-.006 \\
-.004 \\
-.008\end{array}$ & $\begin{array}{l}0.000 \\
-.021 \\
-.064 \\
-.081 \\
-.108\end{array}$ & $\begin{array}{r}0.000 \\
-.023 \\
-.062 \\
-.077 \\
-.107\end{array}$ & $\begin{array}{l}0.000 \\
-.027 \\
-.068 \\
-.080 \\
-.108\end{array}$ & $\begin{array}{r}0.000 \\
-.025 \\
-.064 \\
-.077 \\
-.109\end{array}$ & $\begin{array}{r}0.000 \\
-.025 \\
-.065 \\
-.078 \\
-.108\end{array}$ & $\begin{array}{r}0.000 \\
-.024 \\
-.067 \\
-.082 \\
-.110\end{array}$ & $\begin{array}{l}0.000 \\
-.027 \\
-.072 \\
-.085 \\
-.114\end{array}$ & $\begin{array}{l}0.000 \\
-.026 \\
-.070 \\
-.084 \\
-.112\end{array}$ & $\begin{array}{r}0.000 \\
+.001 \\
+.005 \\
+.006 \\
+.004\end{array}$ & $\begin{array}{l}0.000 \\
-.026 \\
-.068 \\
-.081 \\
-.110\end{array}$ & $\begin{array}{r}0.000 \\
-.005 \\
+.004 \\
.000 \\
+.002\end{array}$ & $\begin{array}{r}0.000 \\
-.024 \\
-.066 \\
-.081 \\
-.09\end{array}$ \\
\hline $\begin{array}{l}4.5 \\
5.0 \\
5.5 \\
6.5 \\
7.5\end{array}$ & $\begin{array}{r}-.137 \\
-.132 \\
-.127 \\
-.108 \\
-.079\end{array}$ & $\begin{array}{l}-.135 \\
-.128 \\
-.127 \\
-.110 \\
-.077\end{array}$ & $\begin{array}{l}-.136 \\
-.130 \\
-.127 \\
-.109 \\
-.078\end{array}$ & $\begin{array}{l}-.133 \\
-.129 \\
-.125 \\
-.108 \\
-.072\end{array}$ & $\begin{array}{l}-.003 \\
-.001 \\
-.002 \\
-.001 \\
-.006\end{array}$ & $\begin{array}{l}-.135 \\
-.130 \\
-.126 \\
-.109 \\
-.075\end{array}$ & $\begin{array}{l}-.136 \\
-.128 \\
-.124 \\
-.109 \\
-.074\end{array}$ & $\begin{array}{l}-.135 \\
-.129 \\
-.124 \\
-.102 \\
-.075\end{array}$ & $\begin{array}{l}-.133 \\
-.125 \\
-.125 \\
-.105 \\
-.073\end{array}$ & $\begin{array}{l}-.135 \\
-.128 \\
-.124 \\
-.105 \\
-.074\end{array}$ & $\begin{array}{l}-.135 \\
-.130 \\
-.127 \\
-.110 \\
-.074\end{array}$ & $\begin{array}{l}-.136 \\
-.129 \\
-.127 \\
-.110 \\
-.074\end{array}$ & $\begin{array}{l}-.136 \\
-.130 \\
-.127 \\
-.110 \\
-.074\end{array}$ & $\begin{array}{r}+.001 \\
+.002 \\
+.003 \\
+.005 \\
.000\end{array}$ & $\begin{array}{l}-.136 \\
-.129 \\
-.126 \\
-.108 \\
-.074\end{array}$ & $\begin{array}{r}+.001 \\
-.001 \\
.000 \\
-.001 \\
-.001\end{array}$ & $\begin{array}{r}-.136 \\
-.130 \\
-.126 \\
-.109 \\
-.075\end{array}$ \\
\hline $\begin{array}{r}8.5 \\
9.5 \\
10.0\end{array}$ & $\begin{array}{r}-.053 \\
-.022 \\
.000\end{array}$ & $\begin{array}{r}-.053 \\
-.021 \\
.000\end{array}$ & $\begin{array}{r}-.053 \\
-.022 \\
.000\end{array}$ & $\begin{array}{r}-.055 \\
-.024 \\
.000\end{array}$ & $\begin{array}{r}+.002 \\
+.002 \\
.000\end{array}$ & $\begin{array}{r}-.054 \\
-.023 \\
.000\end{array}$ & $\begin{array}{r}-.053 \\
-.024 \\
.000\end{array}$ & $\begin{array}{r}-.050 \\
-.022 \\
.000\end{array}$ & $\begin{array}{r}-.049 \\
-.021 \\
.000\end{array}$ & $\begin{array}{r}-.051 \\
-.022 \\
.000\end{array}$ & $\begin{array}{r}-.054 \\
-.020 \\
.000\end{array}$ & $\begin{array}{r}-.054 \\
-.026 \\
.000\end{array}$ & $\begin{array}{r}-.054 \\
-.026 \\
.000\end{array}$ & $\begin{array}{r}+.003 \\
+.004 \\
.000\end{array}$ & $\begin{array}{r}-.053 \\
-.024 \\
.000\end{array}$ & $\begin{array}{r}-.000 \\
+.001 \\
.000\end{array}$ & $\begin{array}{r}-.054 \\
-.024 \\
.000\end{array}$ \\
\hline
\end{tabular}

+ value $=$ convexity $;-$ value $=$ concavity 
The indirect determinations for flat 1 with supports at $0.95 r$ are given in table 1 , columns $8,9,10$, and with supports at $0.66 r$, in columns 12 , and 13 . Columns 11 and 14 give the means of determinations at $0.95 r$ and $0.66 r$, respectively. Column 15 gives the difference between the mean values at $0.95 r$ and $0.66 r$. As with the direct determinations, the individual indirect determinations differ from their respective mean values in the third decimal place, and likewise the differences in their mean values are small notwithstanding the large differences in bending term values applied in the equations. Column 16 gives the mean of the indirect determinations for the flats supported at $0.95 r$ and at $0.66 r$. The small differences between the direct values (col. 7) and the indirect vlaues (col. 16) shown in column. 17 are attributed to experimental errors. Equally small differences between direct and indirect values were obtained for flats 2, 3, and 4. Column 18 gives the true contour of flat 1 , and is taken as the average of the direct and indirect determinations. The true contours of the four standard flats are shown in figure 4.

\subsection{Bending of Flats}

The bending deflection was determined from comparisons of flats 1 and 3 by the method described in section 2.2 .

These flats were supported as previously on 1/8-in.diameter paper disks at three points equidistant from the center of the flat and equidistant from each other. The deviation of a fringe from a straight line was measured for the inner 10-in.-diameter surfaces along a diametric line parallel to two of the supports of each flat: first with flat 1 above; and second with flat 3 above. The measured deviations were $a$ and $a^{\prime}$, respectively.

To determine the effect on bending when the flats were supported at different distances from the center, tests were made with supports at the following distances: 1.0 in. $(0.19 r) ; 1.5$ in. $(0.28 r) ; 2.5$ in. $(0.47 r) ; 3.5$ in. $(0.66 r) ; 4.25$ in. $(0.80 r) ; 5.06$ in. $(0.95 r)$

The bending deflection of flat 1 was calculated from equation $D_{1}=0.743\left(a-a^{\prime}\right)$, except for the $0.19 r$ support, for which no value of $a^{\prime}$ was determined. ${ }^{2}$ The deflection for this support was calculated from $D_{1}=1.483\left[a-\left(C_{1}+C_{3}\right)\right]$, using the values previously determined for $\mathrm{C}_{1}$ and $\mathrm{C}_{3}$.

Figure 5 gives the bending curves for the inner 10-in. surface of flat 1 supported at different distances from the center. "The bending deflection at the center changed from a downward $(+)$ deflection of 0.143 fringe for supports at $0.95 r$ to an upward

\footnotetext{
${ }^{2}$ Support near the center appears to be a severe condition that might cause permanent change in the flat, and therefore should, in general, be avoided. Previous tests of flats supported $0.5 \mathrm{in}$. from the center gave a pronounced peak distortion at the center. In the present instance, flats 1 and 3 were supported for 1 day at $0.19 r$. A month later, when the flats were supported at $0.95 r$ and compared, the measured values for $a$ and $a^{\prime}$ differed from previous values by approximately -0.03 fringe, thus indicating either a permanent or temporary differential change in the flats. During the following month, the flats were supported at $0.95 r$, that is, in a position in which the deflection is in a direction opposite to that with supports near the center. At the end of the month measured values of $a$ and $a^{\prime}$ approached closely the original values, indicating that the change may have been caused wholly or in part by plastic flow of the fused quartz. As a subject for investigation, it appears important to determine, with flats other than
the Bureau's standard planes, the nature of the changes in contour that occur when flats are supported in extreme positions.
}

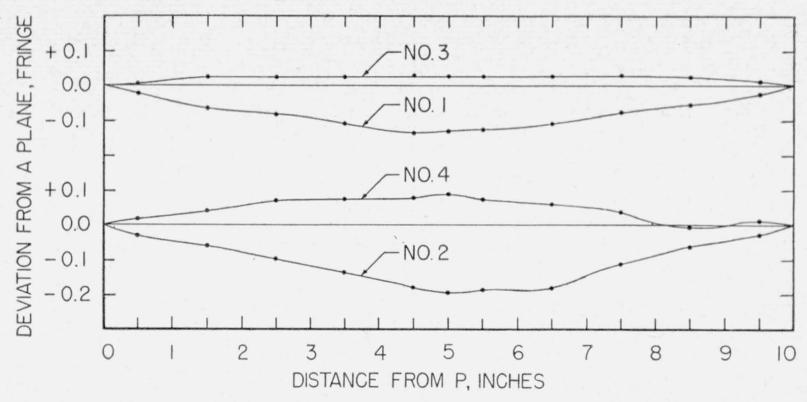

Figure 4. True contours of the four standard optical flats.

(+ Value indicates convexity; - value indicates concavity).

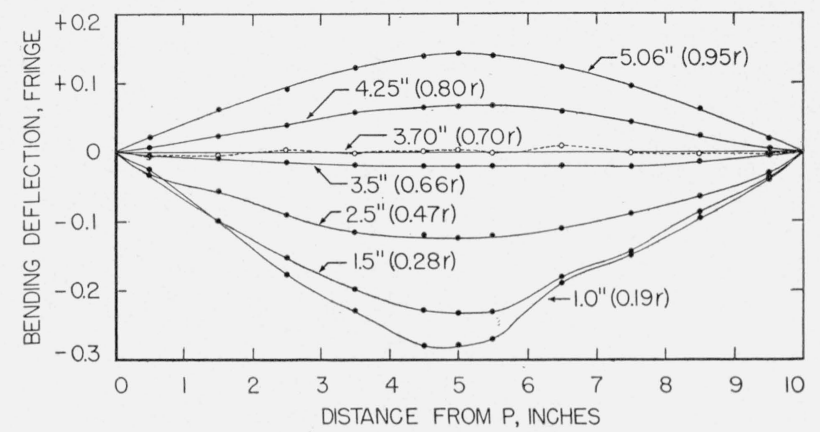

FIGURE 5.-Bending curves for flat Number 1 supported at different distances from its center.

$(+$ Value $=$ downward deflection; - value $=$ upward deflection $)$

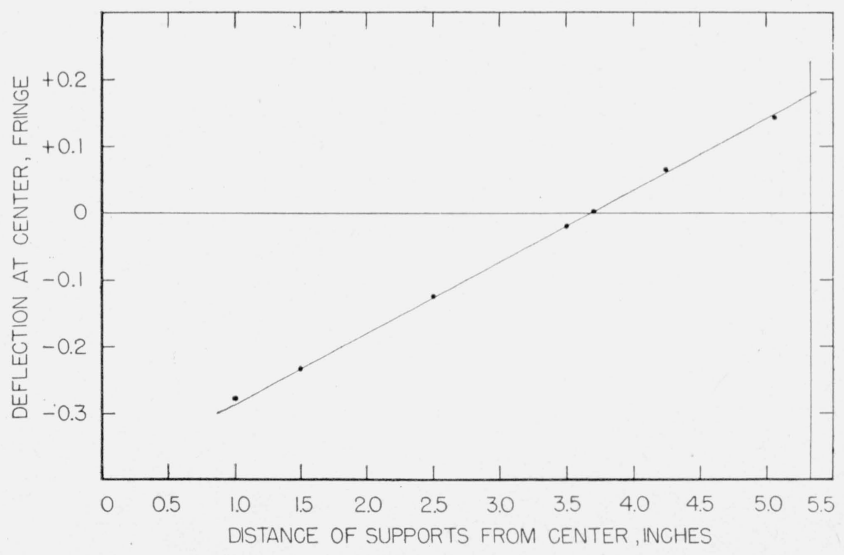

FiguRE 6.-Bending deflection at the center of Number 1 relative to points $\mathrm{P}, \mathrm{P}_{1} 5 \mathrm{in}$. from the center, for supports at different distances from the center.

(-) deflection of 0.278 fringe for supports at $0.19 r$. Inspection of the curves indicated that the bending deflection of a flat supported at $0.70 r$ would be quite small. Determinations were then made for this condition. The results, which are shown with the other curves in figure 5 , indicate that the bending along the diametric line does not exceed 0.01 fringe for flat 1 . The bending of thicker flats 3 and 4 when supported at $0.70 r$ could be considered negligible.

The bending deflections at the center of the surface of flat 1 when plotted for the different supports appear to fall approximately on a straight line, figure 6 . By projecting the line to intersect the circumfer- 
ence of this 10.66-in.-diameter flat, the bending deflection that would result, if the flat were supported at its edge, is obtained. The best value for the bending deflection, $W_{E}$, at the center of flat 1 with respect to points on the diametric line $5 \mathrm{in}$. from the center (that is, for the inner 10-in. surface) when the flat is supported at its edge appears to be

$$
W_{E}=0.177 \text { fringe }=2.05 \times 10^{-6} \text { in. }
$$

The data given in figures 5 and 6 may have application when very accurate comparisons of a standard flat and a test flat of less diameter are required. The test flat in this case may rest on supports at 0.70 of its radius to give minimum bending, and the supports for the standard may be placed in vertical alignment with these. The true contour of the standard may then be corrected by the bending data to give its contour in the position of test.

\section{Comparison of Theoretical and Experi- mental Values for Bending Deflection}

Figure 7 is the theoretical curve for the bending deflection at the center of a 10-in. diameter inner surface of flat 1 along AA with respect to a plane defined by the three symmetrically spaced points of support BBB of a uniformly loaded fused-quartz plate.

Constants for flat $1:^{3} a=5.33$ in.; $h=1.428$ in.; $P=10.18 \mathrm{lb} ; E=10.15 \times 10^{6} \mathrm{psi} ; \nu=0.14$.

From figure $7, w\left(E h^{3} / P a^{2}\right)$ at the center of flat 1 $(r / a=0)$ with respect to a plane through the points of support is 0.424 ; or

$$
w=4.15 \times 10^{-6} \text { in. }
$$

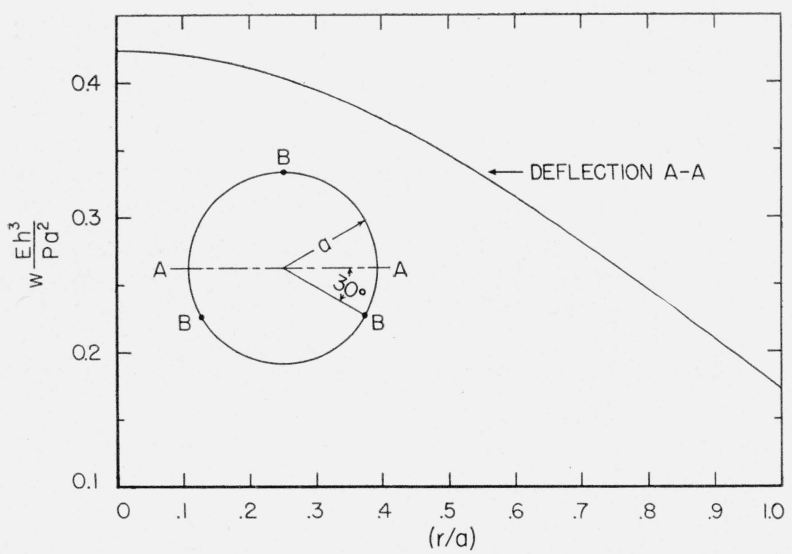

Figure 7. Bending deflection of uniformly loaded plate supported at three equally spaced points on circumference $B B B$.

$\mathrm{E}$, Modulus of elasticity; $\mathrm{P}$, weight of plate; a, radius of plate; $\mathrm{h}$, thickness of plate; $r$, distance from center; v, 0.14, Poisson's ratio for fused quartz; w, deflection along $\mathrm{A}-\mathrm{A}$ relative to $\mathrm{BBB}$.

${ }^{3}$ Values for $E$ and $\nu$ are those considered by Sosman [6] as the best values for used quartz.
Similarly, $w\left(E h^{3} / P a^{2}\right)$ at a point along $\mathrm{AA} 5$ in. from the center $(r / a=0.94)$ is 0.195 ; or

$$
w_{1}=1.91 \times 10^{-6} \text { in. }
$$

The difference between (7) and (8), or $w_{T}$ is the bending deflection at the center of flat 1 with respect to points $\mathrm{P}$ and $\mathrm{P}_{1}$ on $\mathrm{AA}$ that are $5 \mathrm{in}$. from the center; or $w_{T}=2.24 \times 10^{-6}$ in. The corresponding deflection $w_{E}$ determined experimentally (section 4.2 ) is $w_{E}=2.05 \times 10^{-6}$ in.; that is, the theoretical value is between 9 and 10 percent greater than that determined experimentally.

In order to determine the relative shapes of theoretical and experimental bending curves for comparable conditions of support, the deflections given in figure 5 for the bending curve of flat 1 supported at $0.95 r$ were increased by the ratio $177 / 143$ (see section 4.2 ) to approximate the condition of edge support for which the theory applies.

Figure 8 shows that the theoretical and the experimental bending curves are similar in shape but differ in magnitude of the deflections. The values derived by theory average about 11 percent greater than those obtained by the method used in this investigation.

This agreement between the theoretical and the experimental values for bending appears satisfactory in view of the many factors that might influence either result. The experimental values would be affected by small differences in setting the flats, errors of measurement, insufficient number of measurements taken to integrate small local variations in optical surfaces as noted by Saunders [7], and the use of supports of finite size rather than point supports. Likewise, the theoretical values would be different were other values used for $\mathrm{E}$ and $\nu$. The values determined for these elastic constants of fused quartz by different observers vary appreciably as shown in a summary by Sosman [6]. He states, "A study of the assemblage as a whole will show there

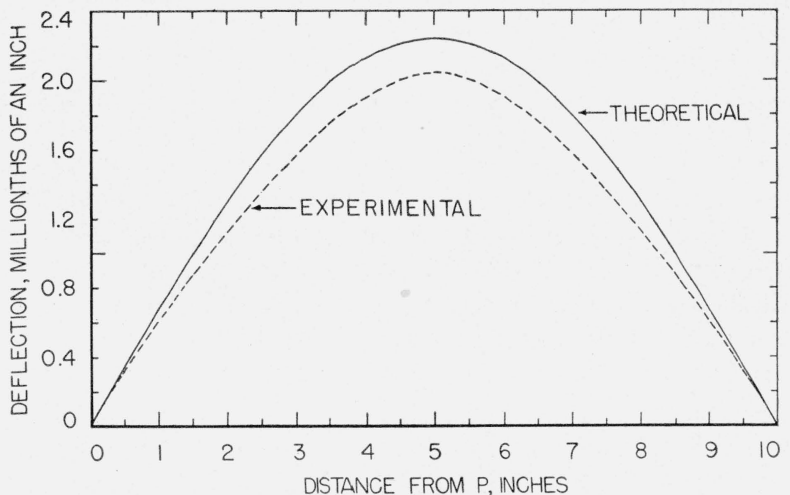

Figure 8.-Theoretical and experimental bending curves of flat Number 1 supported at three equally spaced points on its circumference. The curves give the difference in the bending deflection at points along a diametric line that is parallel to two of the supports and the deflection at points on the same line that are 5 in. from the center of the flat. Bending deflections relative to the points of support may be obtained by increasing the theoretical values $1.91 \times 10^{-6} \mathrm{in}$. and by increasing the experimental values $1.7 \times 10^{-6} \mathrm{in}$. 
is not much consistency, either in the theory or experiment among the various values. Part of the reason, I feel sure, is that the usual specimen of vitreous silica is not structurally isotropic, as we have been assuming, but is to a greater or less degree aeolotropic." From this consideration alone, the values of $\nu$ and $\mathbf{E}$ used to calculate the theoretical bending may not apply to the standard flats.

Substitution of the theoretical value for bending for the experimental value would change the true contour at the center of flat 1 , as given in table 1 for supports at $0.95 \mathrm{r}$, by 0.01 fringe in those cases where corrections of 2.07D are applied, and would vitiate to some extent the excellent agreement of direct and indirect determinations of contour. The determined bending deflection values may, therefore, be more applicable to the present flats and their conditions of test than the theoretical ones.

\section{Effect of Supports of Finite Size}

When flats supported on balls are compared, a series of interference fringes concentric about the point of contact of support and surface is visible, indicating an appreciable deformation of the surface concentrated at the point of contact. The reason for using 1/8-in-diameter paper supports in the present work was to distribute the load over a larger area and thereby avoid damage to the flats. Local distortion of the surface surrounding the disks for about $3 / 32$ in. beyond the supports was evident when viewing the fringes. At the edge of a disk, the surface of the flat was depressed about 0.3 fringe. It is quite reasonable that the deflection may be somewhat less when flats are supported on the disks rather than points, thus giving a lower value than that required by theory. To test this, from consideration of contour, bending, shear, local deformation at the supports, and thickness of the flats, the following equation was derived, in which contour, shear, and the effect of the supports are eliminated.

$$
\frac{D_{\mathrm{in} .}}{t_{x}^{2}}=\frac{1}{2} \frac{\frac{b^{\prime}-b}{t_{z}-t_{x}}-\frac{a^{\prime}-a}{t_{y}-t_{x}}}{\frac{t_{x}+t_{y}}{t_{y}^{2}}-\frac{t_{x}+t_{z}}{t_{z}^{2}}},
$$

in which $D_{\text {in }}$ is the bending deflection of a plate $1 \mathrm{in}$. thick and $\mathrm{t}_{x}, \mathrm{t}_{y}, \mathrm{t}_{z}=$ thickness of plates $\mathrm{X}, \mathrm{Y}, \mathrm{Z}$, and $D_{\mathrm{In} .} / t_{x}^{2}$ is the bending deflection of $\mathrm{X}$. From comparisons of $\mathrm{X}$ and $\mathrm{Y}: a$ is the deviation of $\mathrm{a}$ fringe from a straight line, with $\mathrm{X}$ above, and $a^{\prime}$ is the deviation of a fringe from a straight line, with $\mathrm{Y}$ above. From comparisons of $\mathrm{X}$ and $\mathrm{Z}: \quad b$ is the measured deviation, with $\mathrm{X}$ above, and $b^{\prime}$ is the measured deviation, with $\mathrm{Z}$ above.

The difference between the values for bending previously determined and those by this method was less than the experimental error of this method. No effect of local deformation on the bending deflection was therefore indicated by these experiments.

The excellent agreement between contours obtained with support at $0.95 r$ and at $0.66 r$, table 1 , indicates that local deformation near the supports had negligible effect on the contour measurements.

\section{Conclusion}

Precise calibration of optical flats requires that account be taken of the surface distortion that results when the flats are supported in their position of test. For a 10 5/8-in.-diameter, 1 7/16-in.-thick fusedquartz optical flat supported at three equally spaced points at its edge, the gravitational bending deflection at the center of the flat with respect to its points of support will be approximately $4 \times 10^{-6}$ in. To reduce this to $1 \times 10^{-6}$ in. ( 0.1 fringe) would require a thickness of $2.9 \mathrm{in}$. on the basis of theoretical computations, which agree quite closely with experimental determinations. The bending deflection will increase appreciably for larger flats because it varies directly as the fourth power of the radius. For three-point support, bending is small and at a minimum when the supports lie on the circumference of a circle having a radius 0.7 that of the flat.

Whenever two flats of the same material and diameter but of different thicknesses are available and can be similarly supported during comparison, the bending deflection of each flat may be determined by the described methods. Likewise, if three flats of the same material and diameter are available, very precise determinations of the true contours, undistorted by bending of their surfaces, may be determined.

The author expresses his deep appreciation to Samuel Levy of the Engineering Mechanics Section of the Bureau for his cooperation in the theoretical determinations of the deflection of plates that were used in this investigation and for his many helpful suggestions.

\section{References}

[1] A. Nádai, Die Verbiegungen in einzelmen Punkten unterstuetzter kreisfoermiger Platten, Physik. Z. 23, (1922).

[2] A. Nádai, Theorie der Plattenbiegung und ihre experimentelle Best"tigung, Z. angew. Math. Mech. 2, 381394, (1922).

[3] A. Nádai, Elastische Platten (Berlin, J. Springer, p. 196, 1925).

[4] S. Timoshenko, Theory of plates and shells, p. 61-63; 80; 271 (McGraw-Hill Book Co., Inc., New York and London, 1940).

[5] C. Pulfrich, Z. Instr. 18, 261, (1898).

[6] R. B. Sosman, Properties of silica, 437 (The Chemical Catalog Co., Inc., New York, N. Y., 1927).

[7] J. B. Saunders, Contour mapping of optical surfaces with light waves, J. Research NBS 47, 148 (1951) RP2239.

Washington, May 27, 1952. 